\title{
Evolution and thermodynamics of the slow unfolding of hyperstable monomeric proteins
}

\author{
Jun Okada', Tomohiro Okamoto', Atsushi Mukaiyama', Takashi Tadokoro', Dong-Ju You', Hyongi Chon', \\ Yuichi Koga' ${ }^{1}$ Kazufumi Takano*1,2 and Shigenori Kanaya'
}

\begin{abstract}
Background: The unfolding speed of some hyperthermophilic proteins is dramatically lower than that of their mesostable homologs. Ribonuclease HII from the hyperthermophilic archaeon Thermococcus kodakaraensis (Tk-RNase HII) is stabilized by its remarkably slow unfolding rate, whereas RNase HI from the thermophilic bacterium Thermus thermophilus (Tt-RNase HI) unfolds rapidly, comparable with to that of RNase HI from Escherichia coli (Ec-RNase HI).

Results: To clarify whether the difference in the unfolding rate is due to differences in the types of RNase Hor differences in proteins from archaea and bacteria, we examined the equilibrium stability and unfolding reaction of RNases HII from the hyperthermophilic bacteria Thermotoga maritima (Tm-RNase HII) and Aquifex aeolicus (Aa-RNase HII) and RNase HI from the hyperthermophilic archaeon Sulfolobus tokodaii (Sto-RNase HI). These proteins from hyperthermophiles are more stable than Ec-RNase HI over all the temperature ranges examined. The observed unfolding speeds of all hyperstable proteins at the different denaturant concentrations studied are much lower than those of Ec-RNase HI, which is in accordance with the familiar slow unfolding of hyperstable proteins. However, the unfolding rate constants of these RNases $\mathrm{H}$ in water are dispersed, and the unfolding rate constant of thermophilic archaeal proteins is lower than that of thermophilic bacterial proteins.
\end{abstract}

Conclusions: These results suggest that the nature of slow unfolding of thermophilic proteins is determined by the evolutionary history of the organisms involved. The unfolding rate constants in water are related to the amount of buried hydrophobic residues in the tertiary structure.

\section{Background}

Proteins from thermophiles and hyperthermophiles generally exhibit higher stability than their mesostable counterparts [1-4]. Recent research in this field has indicated that some proteins from hyperthermophiles are stabilized by their remarkably slow unfolding rates [5-17]. At present, the molecular mechanism of slow unfolding is not completely clear. Recently, using hydrophobic mutant proteins, Dong et al. [18] demonstrated that the hydrophobic effect is one of the reasons for the slow unfolding of ribonuclease HII from the hyperthermophilic archaeon Thermococcus kodakaraensis (Tk-RNase HII). However, the attributes of proteins that exhibit unusually slow unfolding are unclear. For example, Tk-RNase HII is kinetically robust [19], whereas RNase HI from the ther-

\footnotetext{
*Correspondence: ktakano@mls.eng.osaka-u.ac.jp

1 Department of Material and Life Science, Osaka University, 2-1 Yamadaoka, Suita, Osaka 565-0871, Japan

Full list of author information is available at the end of the article
}

mophilic bacterium Thermus thermophilus (Tt-RNase $\mathrm{HI}$ ), which has equivalent thermostability but no sequence similarity to Tk-RNase HII, unfolds rapidly. Moreover, the unfolding rate of Tt-RNase $\mathrm{HI}$ is comparable with to that of RNase HI from Escherichia coli (EcRNase HI) $[20,21]$. The reason for the difference in the unfolding rate is unknown.

Both equilibrium stability and kinetic unfolding/refolding experiments can improve our understanding of the nature of hyperstable proteins. Luke et al. [22] listed the hyperthermophilic proteins for which kinetic folding/ unfolding parameters have been reported. These are generally oligomers or monomers that show irreversible unfolding. Monomeric proteins with reversible unfolding are suitable for detailed analysis of the essentials of slow unfolding. Only RNase $\mathrm{H}$, cold shock protein (Csp), and ribosomal protein S16 (S16) satisfy these prerequisites [23]. Csp from the hyperthermophilic bacterium Thermotoga maritima (Tm-Csp) and ribosomal protein S16 
from the hyperthermophilic bacterium Aquifex aeolicus (Aa-S16) do not exhibit extremely slow unfolding [24-27]. Data for the unfolding kinetics of RNase H, Csp, and S16 suggest that differences in the type of protein, i.e., whether it is RNase HI or RNase HII, or differences in the organism kingdom, i.e., whether the host organism to which the protein belongs originates from archaea or bacteria, may be the reason for the differences in the unfolding reactions of Tk-RNase HII and Tt-RNase HI.

Based on their sequence similarity, RNases $\mathrm{H}$ are classified into two major types--Type $1 \mathrm{RNase} \mathrm{H}$ and Type 2 RNase $H[28,29]$. RNase $H I$ is a member of Type 1 RNase $\mathrm{H}$, whereas RNase HII is a member of Type 2 RNase $\mathrm{H}$. Comparison of the crystal structures of Ec-RNase HI, TtRNase HI, and Tk-RNase HII indicates that these enzymes share a folding motif referred to as the RNase $\mathrm{H}$ fold due to its characterization in Ec-RNase HI [30], although there is no sequence similarity between RNase $\mathrm{HI}$ and RNase HII. The stability and folding of Ec-RNase HI, Tt-RNase HI, and Tk-RNase HII have been well studied [18-21,31-40].

Archaea and bacteria have divided at an early stage of evolution [41]. Hyperthermophiles and thermophiles in archaea originated in a hot environment but those in bacteria recolonized at a later stage under extreme conditions. The differences in the unfolding characteristics of hyperstable proteins may be ascribed to such differences in the evolutionary history of thermophilic archaea and bacteria.

In this study, we focused on Tm-RNase HII, Aa-RNase HII, and Sto-RNase HI (Sulfolobus tokodaii) and compared these proteins with Tk-RNase HII, Tt-RNase HI, and Ec-RNase $\mathrm{HI}$ in terms of their stability and unfolding kinetics [19-21,31]. Tm-RNase HII and Aa-RNase HII are proteins from hyperthermophilic bacteria and are Type 2 RNase $\mathrm{H}$ proteins. Sto-RNase $\mathrm{HI}$ is a protein from a hyperthermophilic archaeon and is a Type 1 RNase H. All these proteins are monomeric. Table 1 summarizes the types and origins of RNases $\mathrm{H}$ studied in this paper. The crystal structures of Ec-RNase HI, Tt-RNase HI, StoRNase HI, Tk-RNase HII, and Tm-RNase HII have already been determined (PDB ID 2RN2, 1RIL, 2EHG, 1IO2, and 2ETI) [42-45] (see additional file 1). We used circular dichroism (CD) to study the equilibrium stability and kinetic aspects of guanidine hydrochloride (Gdn$\mathrm{HCl}$ )-induced unfolding of Tm-RNase HII, Aa-RNase HII, and Sto-RNase HI. These proteins exhibited reversible unfolding during $\mathrm{GdnHCl}$-induced unfolding. The unfolding of these hyperthermophilic origin RNases $\mathrm{H}$ induced by $\mathrm{GdnHCl}$ concentration jumps is apparently quite slow and similar to that of several hyperthermophilic proteins that exhibit irreversible unfolding. However, the unfolding rate constant in water depends on the kingdom (archaea or bacteria) to which the host microor- ganisms belong. Based on the results obtained, we discuss the origin of slow unfolding in relation to the attributes of the proteins.

\section{Results}

\section{$\mathrm{CD}$ spectra and reversible unfolding in $\mathrm{GdnHCl}$}

The far-UV spectra of Tm-RNase HII, Aa-RNase HII, and Sto-RNase $\mathrm{HI}$ were recorded in the absence and presence of $\mathrm{GdnHCl}$ at $25^{\circ} \mathrm{C}$ (see additional file 2). The spectra represent the proteins in their native and $\mathrm{GdnHCl}$ denatured states in the absence and presence of $\mathrm{GdnHCl}$. The spectra of the folded condition obtained from the denatured state by dilution of $\mathrm{GdnHCl}$ were also recorded. The results demonstrate that $\mathrm{GdnHCl}$-induced unfolding of these proteins is almost completely reversible under each condition (see additional file 2). Experiments on $\mathrm{GdnHCl}$-induced unfolding of these proteins were carried out under conditions of reversible unfolding (see below). It has been shown that Tk-RNase HII, Tt-RNase $\mathrm{HI}$, and Ec-RNase $\mathrm{HI}$ undergo reversible unfolding in the presence of denaturants [19,20,31]. RNases $\mathrm{H}$ are considered to be good models for clarifying the mechanisms of conformational stability and folding of hyperstable proteins. RNase HI from the psychotrophic bacterium Shewanella onedensis MR-1 was also shown to unfold reversibly in the presence of chemical denaturants [46$48]$.

\section{Equilibrium stability of $\mathrm{GdnHCl}$-induced unfolding and stability profile}

The equilibrium stabilities of Tm-RNase HII, Aa-RNase HII, and Sto-RNase HI were evaluated by GdnHClinduced denaturation, and the changes were monitored by $\mathrm{CD}$ at various temperatures (see additional file 3 ). Reactions reached equilibrium within 3 days for TmRNase HII and Aa-RNase HII and within 3 weeks for StoRNase HI, suggesting that the unfolding of these proteins was slow. These proteins exhibit a two-state transition. The $\Delta \mathrm{G}\left(\mathrm{H}_{2} \mathrm{O}\right)$ value at each temperature was calculated using Eqs. (1) and (2). The resultant $\Delta \mathrm{G}\left(\mathrm{H}_{2} \mathrm{O}\right)$ values were plotted as a function of the temperature (stability profile) in Figure 1 and were fitted to Eq. (3). When fitting these values to Eq. (3), the $\mathrm{T}_{\mathrm{m}}$ value, which is the thermal denaturation temperature obtained from the heatinduced unfolding experiment (see below), was used $\left(\Delta \mathrm{G}\left(\mathrm{H}_{2} \mathrm{O}\right)=0\right.$ at $\left.\mathrm{T}_{\mathrm{m}}\right)$. Figure 1 shows the data for TkRNase HII, Tt-RNase HI, and Ec-RNase HI. The values of $\mathrm{T}_{\mathrm{m}}, \Delta \mathrm{C}_{\mathrm{p}}, \Delta \mathrm{H}_{\mathrm{m}}, \mathrm{T}_{\mathrm{s}}$, and $\Delta \mathrm{G}\left(\mathrm{T}_{\mathrm{s}}\right)$ of RNases $\mathrm{H}$ are summarized in Table 2. $\Delta \mathrm{C}_{\mathrm{p}}$ represents the difference in the heat capacity of the native and unfolded states; $\Delta \mathrm{H}_{\mathrm{m}}$ is the enthalpy change of the unfolding at $\mathrm{T}_{\mathrm{m}} ; \mathrm{T}_{\mathrm{s}}$ is the temperature at which the protein exhibits the maximal $\Delta \mathrm{G}\left(\mathrm{H}_{2} \mathrm{O}\right)$ value; and $\Delta \mathrm{G}\left(\mathrm{T}_{\mathrm{s}}\right)$ is the $\Delta \mathrm{G}\left(\mathrm{H}_{2} \mathrm{O}\right)$ value at $\mathrm{T}_{\mathrm{s}}$. 
Table 1: Types and origins of RNases $H$.

\begin{tabular}{|c|c|c|}
\hline & Archaea & Bacteria \\
\hline \multirow[t]{2}{*}{$\begin{array}{c}\text { Type } 1 \\
\text { RNase HI }\end{array}$} & $\begin{array}{l}\text { Sto; Sulfolobus tokodaii } \\
\text { (hyperthermophile) }\end{array}$ & $\begin{array}{l}\text { Ec; Escherichia coli } \\
\text { (mesophile) }\end{array}$ \\
\hline & & $\begin{array}{c}\mathrm{Tt} ; \text { Thermus thermophilus } \\
\text { (thermophile) }\end{array}$ \\
\hline \multirow[t]{2}{*}{$\begin{array}{c}\text { Type } 2 \\
\text { RNase HII }\end{array}$} & $\begin{array}{c}\text { Tk; Thermococcus kodakaraensis } \\
\text { (hyperthermophile) }\end{array}$ & $\begin{array}{l}\text { Aa; Aquifex aeolicus } \\
\text { (hyperthermophile) }^{\text {a }}\end{array}$ \\
\hline & & $\begin{array}{l}\text { Tm; Thermotoga maritima } \\
\text { (hyperthermophile) }\end{array}$ \\
\hline
\end{tabular}

a This work.

RNases $\mathrm{H}$ from thermophiles and hyperthermophiles are more stable than Ec-RNase HI over most of the temperature ranges examined. In particular, Sto-RNase HI has much higher stability. However, the thermodynamic parameters and stabilization mechanism from the viewpoint of equilibrium stability for the hyperstable RNases $\mathrm{H}$ differ depending on the proteins (see Discussion below).

\section{Thermal stability of heat-induced unfolding}

Heat-induced unfolding of Sto-RNase HI has already been analyzed by differential scanning calorimetry (DSC) [44]. The $\mathrm{T}_{\mathrm{m}}$ of Sto-RNase HI is $102.0^{\circ} \mathrm{C}$. The thermal denaturation curves of Tm-RNase HII and Aa-RNase HII were recorded by measuring the change in $\mathrm{CD}$. The thermal denaturation of these proteins was almost completely reversible in the presence of various concentrations of $\mathrm{GdnHCl}$ (see Methods). $\mathrm{T}_{\mathrm{m}}$ was calculated by curve fitting the resultant $\mathrm{CD}$ spectrum versus temperature based on a least-squares analysis using Eq. (4). The $T_{m}$ values of Tm-RNase HII and Aa-RNase HII in the absence of Gdn$\mathrm{HCl}$ were estimated to be $78.6^{\circ} \mathrm{C}$ and $84.0^{\circ} \mathrm{C}$, respectively, and were comparable to those of Tt-RNase HII $\left(86.0^{\circ} \mathrm{C}\right)$ and Tk-RNase HII $\left(82.8^{\circ} \mathrm{C}\right)[19,20]$.

\section{Kinetics of $\mathrm{GdnHCl}$-induced unfolding}

The kinetics of GdnHCl-induced unfolding of Tm-RNase HII, Aa-RNase HII, and Sto-RNase HI were measured at $25^{\circ} \mathrm{C}$. The reaction was initiated by jumps to various $\mathrm{GdnHCl}$ concentrations followed by $\mathrm{CD}$ measurements. The representative curves were plotted, as shown in Figure . All kinetic traces are described well by a single exponential. Figure shows the $\mathrm{GdnHCl}$ concentration dependence of the logarithms of the apparent rate constant $\left(\mathrm{k}_{\mathrm{app}}\right)$ for the unfolding of RNases $\mathrm{H}$. The logarithms of $\mathrm{k}_{\text {app }}$ linearly increase with an increase in the $\mathrm{GdnHCl}$ concentration. Figure also shows the $\mathrm{GdnHCl}$-induced unfolding data for Tk-RNase HII and Ec-RNase HI. The $k_{\text {app }}$ values for RNases $\mathrm{H}$ from hyperthermophiles were significantly lower than those of Ec-RNase $\mathrm{HI}$ at all the $\mathrm{GdnHCl}$ concentrations examined. By fitting the data to Eq. (6), $\mathrm{k}_{\mathrm{u}}\left(\mathrm{H}_{2} \mathrm{O}\right)$, which is the rate constant for unfolding in the absence of $\mathrm{GdnHCl}$, and $\mathrm{m}_{\mathrm{u}}$, which is the slope of the linear correlation of $\ln \mathrm{k}_{\mathrm{u}}$ with the $\mathrm{GdnHCl}$ concen-

Table 2: Comparison of the thermodynamic parameters of Tm-, Aa-, Tk-RNases HII and Sto-, Tt-, Ec-RNases HI.

\begin{tabular}{|c|c|c|c|c|c|c|}
\hline & \multicolumn{3}{|c|}{ RNase HII } & \multicolumn{3}{|c|}{ RNase HI } \\
\hline & $\mathrm{Tm}$ & $\mathbf{A a}$ & $T^{a}{ }^{a}$ & Sto & $T t^{b}$ & $E^{b}{ }^{b}$ \\
\hline $\mathrm{T}_{\mathrm{m}}\left({ }^{\circ} \mathrm{C}\right)$ & 78.6 & 84.0 & 82.8 & 102.0 & 86.0 & 66.0 \\
\hline 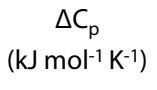 & $7.3 \pm 0.6$ & $10.4 \pm 0.6$ & $14.5 \pm 1.8$ & $11.9 \pm 1.2$ & $7.5 \pm 0.4$ & $11.3 \pm 0.8$ \\
\hline $\begin{array}{c}\Delta \mathrm{H}_{\mathrm{m}} \\
\left(\mathrm{kJ} \mathrm{mol} \mathrm{mol}^{-1}\right)\end{array}$ & $471 \pm 19$ & $549 \pm 21$ & $745 \pm 49$ & $858 \pm 45$ & $548 \pm 21$ & $502 \pm 17$ \\
\hline $\mathrm{T}_{\mathrm{s}}\left({ }^{\circ} \mathrm{C}\right)$ & 19.3 & 35.2 & 40.0 & 37.4 & 20.0 & 24.0 \\
\hline $\begin{array}{c}\Delta \mathrm{G}\left(\mathrm{T}_{\mathrm{s}}\right) \\
\left(\mathrm{kJ} \mathrm{mol}^{-1}\right)\end{array}$ & 40.7 & 38.5 & 51.2 & 77.5 & 53.1 & 31.3 \\
\hline
\end{tabular}




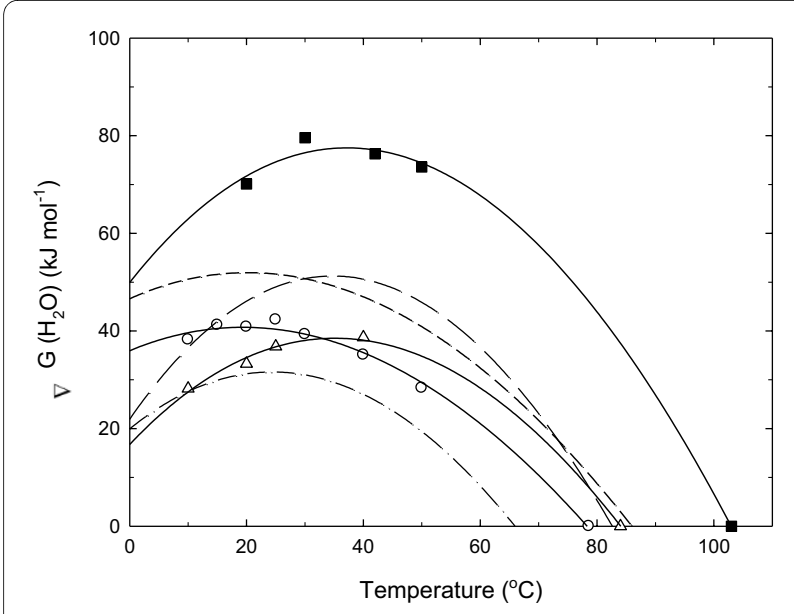

Figure 1 Thermodynamic stability profiles of RNases $\mathrm{H}$. Open circles represent the temperature dependence of $\Delta \mathrm{G}\left(\mathrm{H}_{2} \mathrm{O}\right)$ of Tm-RNase $\mathrm{HII}$ at pH 7.5; open triangles, those of Aa-RNase HII at pH 5.0; and closed squares, those of Sto-RNase $\mathrm{HI}$ at $\mathrm{pH}$ 3.0. The $\mathrm{T}_{\mathrm{m}}$ at which $\Delta \mathrm{G}\left(\mathrm{H}_{2} \mathrm{O}\right)$ becomes zero were estimated from the heat-induced unfolding experiments. The lines represent the fit of Eq. (3). Long-dashed line represents the stability profiles of Tk-RNase HII; the short-dashed line, that of Tt-RNase Hl; and the one-point dashed line, that of Ec-RNase HI $[19,20]$.

tration, were calculated. These values are listed in Table 3 . Figure shows the urea-induced unfolding data for EcRNase HI and Tt-RNase HI [21,33]. The $\mathrm{k}_{\mathrm{u}}\left(\mathrm{H}_{2} \mathrm{O}\right)$ values for RNases $\mathrm{H}$ are dispersed over six orders of magnitude. The $k_{u}\left(\mathrm{H}_{2} \mathrm{O}\right)$ value of Aa-RNase HII is similar to that of Ec-RNase HI, whereas the unfolding of Tk-RNase HII and Sto-RNase HI is remarkably slow.

\section{Discussion}

Proteins from hyperthermophiles often exhibit slower unfolding than those from organisms that grow at moderate temperatures [5-17]. However, the extent of the decrease in the unfolding rate of hyperthermophilic proteins relative to that of their mesophilic counterparts varies, depending on the type of protein involved. The attributes of proteins that exhibit unusually slow unfolding have not been elucidated. In this study, we attempted to characterize super slow unfolding and elucidate its mechanism by examining several RNase $\mathrm{H}$ proteins from thermophiles and hyperthermophiles.

\section{Equilibrium stability of hyperstable RNases $\mathrm{H}$}

The stability of proteins in solution is quantitatively evaluated by the Gibbs energy changes $(\Delta G)$ observed upon unfolding when the reaction is reversible under experimental conditions. The temperature dependence of $\Delta G$ (stability profile) provides some information on the thermodynamic stability of proteins and can be expressed by Eq. (3).

Three thermodynamic models have been proposed to explain the high stability of thermostable proteins [49]. In the first model, the entire stability curve is raised to a higher $\Delta \mathrm{G}$; in the second, the stability curve is flattened; and in the third, the curve is shifted to a higher temperature. Adherence to all three models is observed in nature, and in many cases, proteins from hyperthermophiles utilize various combinations of these mechanisms [50-55]. The outcome depends on the model used to adapt the proteins to a high temperature.

RNases $\mathrm{H}$ from thermophiles and hyperthermophiles are more stable than Ec-RNase HI over most of the temperature ranges examined (Figure 1). In the case of hyperstable RNases HI, Tt-RNase HI adopts the first and second models, and Sto-RNase HI uses the first and third models (Figure 1 and Table 2). There is no data on mesophilic RNase HII. Among the hyperthermophilic RNases HII, Tm-RNase HII has a flatter curve than Aa-RNase HII and Tk-RNase HII as a result of its lower $\Delta C_{p}$. The $T_{s}$ value of Tm-RNase HII is also lower than that of AaRNase HII and Tk-RNase HII. However, $\Delta G\left(T_{s}\right)$ of TkRNase HII is higher than that of Tm-RNase HII and AaRNase HII. These results suggest that the thermodynamic stabilization of RNases $\mathrm{H}$ from thermophiles and hyperthermophiles is achieved through different mechanisms.

Table 3: Comparison of the kinetic parameters of Tm-, Aa-, Tk-RNases HII and Sto-, Tt-, Ec-RNases $\mathrm{HI}$ at $25^{\circ} \mathrm{C}$.

\begin{tabular}{|c|c|c|c|c|c|c|}
\hline & \multicolumn{3}{|c|}{ RNase HII } & \multicolumn{3}{|c|}{ RNase HI } \\
\hline & Tm & Aa & $T^{a}{ }^{a}$ & Sto & Tt & $E c^{\mathbf{b}}$ \\
\hline $\mathrm{k}_{\mathrm{u}}\left(\mathrm{H}_{2} \mathrm{O}\right)\left(\mathrm{s}^{-1}\right)$ & $6.5 \times 10^{-7}$ & $3.7 \times 10^{-5}$ & $6.0 \times 10^{-10}$ & $5.7 \times 10^{-11}$ & $\left(1.3 \times 10^{-5}\right)^{c}$ & $\begin{array}{c}1.1 \times 10^{-5} \\
\left(1.7 \times 10^{-5}\right)^{d}\end{array}$ \\
\hline $\begin{array}{c}\mathrm{m}_{\mathrm{u}} \\
\left(\mathrm{M}^{-1} \mathrm{~s}^{-1}\right)\end{array}$ & 1.46 & 1.08 & 3.29 & 2.14 & - & 3.66 \\
\hline
\end{tabular}

\footnotetext{
a Data from ref. [19].

b Data from ref. [31].

c Data from ref. [21]. The $\mathrm{k}_{\mathrm{u}}\left(\mathrm{H}_{2} \mathrm{O}\right)$ value was obtained from the urea-induced unfolding experiments.

d Data from ref. [33]. The $\mathrm{k}_{\mathrm{u}}\left(\mathrm{H}_{2} \mathrm{O}\right)$ value was obtained from the urea-induced unfolding experiments.
} 


\section{Unfolding of hyperstable RNases $\mathrm{H}$ induced by $\mathrm{GdnHCl}$ concentration jump}

Globular proteins usually unfold in the presence of Gdn$\mathrm{HCl}$. Unfolding takes less than $1 \mathrm{~min}$ in most small globular proteins. To measure such fast unfolding rates, a stopped-flow instrument is required. Ec-RNase $\mathrm{HI}$ is unfolded within $10 \mathrm{~s}$ by a final concentration of $3.0 \mathrm{M}$ $\mathrm{GdnHCl}$ [31]. In contrast, the unfolding of some hyperstable proteins may take a few hours to several days. Pyrrolidone carboxyl peptidase from the hyperthermophilic archaeon Pyrococcus furiosus (Pf-PCP) is unfolded over a period of 1 day or more by a final concentration of $7.7 \mathrm{M}$ $\mathrm{GdnHCl}$ [6], and the unfolding of Tk-RNase HII by a final concentration of 3.9 M GdnHCl requires $2 \mathrm{~h}$ [19]. The observed unfolding of all hyperstable proteins examined here is much slower than that of Ec-RNase HI in the presence of $\mathrm{GdnHCl}$ (Figures 2 and 3). For example, TmRNase HII is unfolded by $4.8 \mathrm{M} \mathrm{GdnHCl}$ within approximately $2 \mathrm{~h}$; Aa-RNase HII is unfolded by $3.5 \mathrm{M} \mathrm{GdnHCl}$ within $1 \mathrm{~h}$; and Sto-RNase HI is unfolded by 7.0 M Gdn$\mathrm{HCl}$ within about $8 \mathrm{~h}$. Our results suggest that such super slow unfolding in the presence of a chemical denaturant might be a common strategy for achieving higher stability and could be related to the adaptation of hyperthermophilic RNases $H$ to higher temperatures.

\section{Estimation of the unfolding speed of hyperstable RNases $\mathrm{H}$ at zero denaturant concentration}

All the RNases $\mathrm{H}$ from the hyperthermophiles examined showed a remarkably slow rate of unfolding in the presence of $\mathrm{GdnHCl}$, as described above. However, the dependencies of the apparent rate constants of the unfolding reactions on the $\mathrm{GdnHCl}$ concentration varied according to the type of protein (Figure 3). By extrapolating the unfolding rate constants to zero, the denaturant concentration yields the semilogarithmic unfolding rate constants in water $\left(\ln _{\mathrm{u}}\left(\mathrm{H}_{2} \mathrm{O}\right)\right)$. It has been reported that $\mathrm{k}_{\mathrm{u}}\left(\mathrm{H}_{2} \mathrm{O}\right)$ at $25^{\circ} \mathrm{C}$ is $1.1 \times 10^{-5} \mathrm{~s}^{-1}$ for $\mathrm{GdnHCl}$-induced unfolding and $1.7 \times 10^{-5} \mathrm{~s}^{-1}$ for urea-induced unfolding of Ec-RNase HI. Furthermore, the values are $1.3 \times 10^{-5} \mathrm{~s}^{-1}$ for urea-induced unfolding of Tt-RNase $\mathrm{HI}$ and $6.0 \times 10^{-10} \mathrm{~s}^{-1}$ for GdnHCl-induced unfolding of Tk-RNase HII $[19,21,31,33]$. These values indicate that Tt-RNase HI unfolds in water on a time scale similar to that of EcRNase HI; however, the unfolding rate of Tk-RNase HII is dramatically lower than that of Ec-RNase HI. Therefore, the unfolding of Tk-RNase HII is much slower than that of Tt-RNase HI, although the equilibrium stabilities of TtRNase HI and Tk-RNase HII are comparable. Furthermore, although there are no unfolding kinetics data for Ec-RNase HII, it is possible that Ec-RNase HII may not exhibit slow unfolding because Ec-RNase HII is less stable than Ec-RNase HI [56].
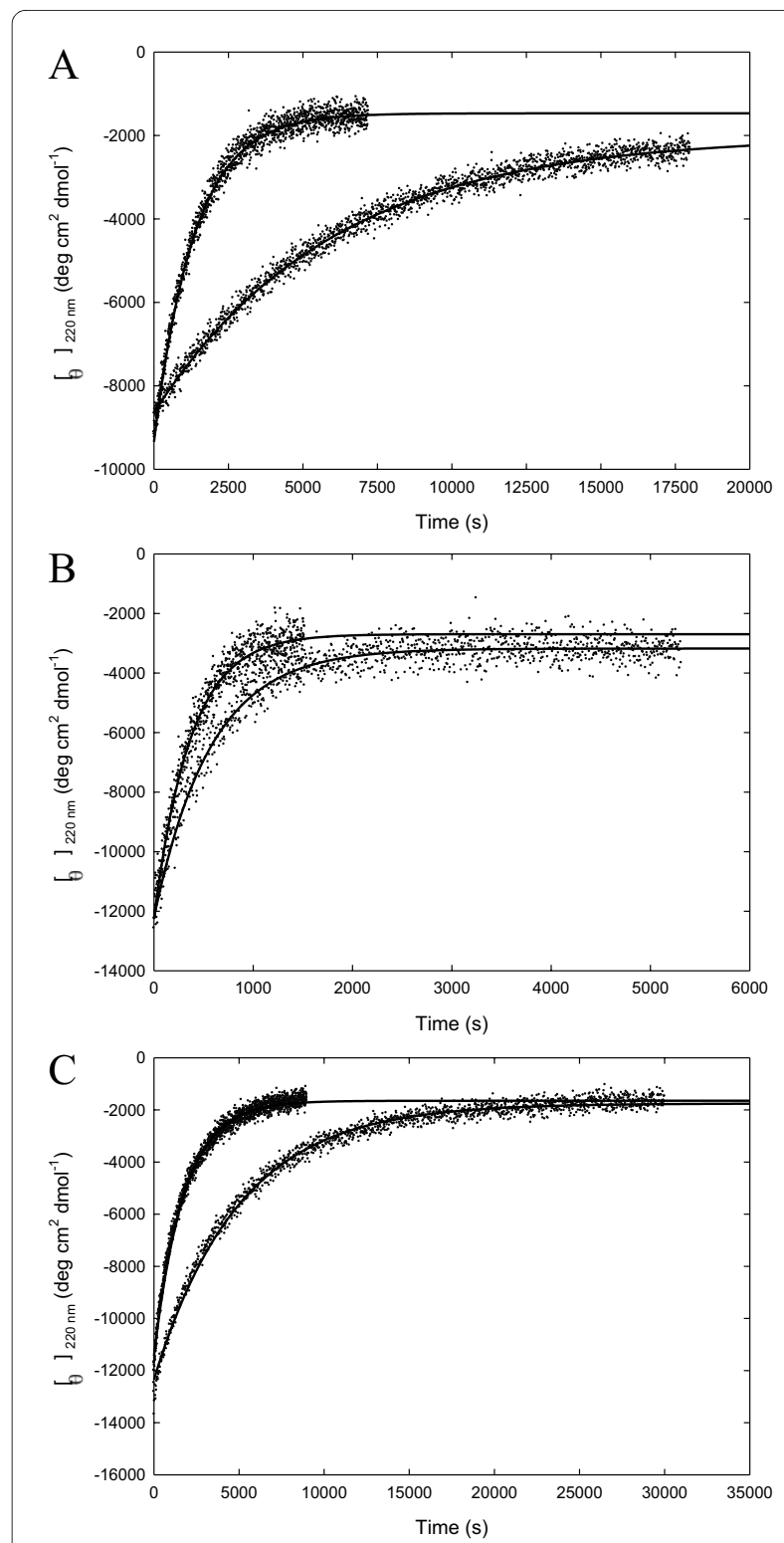

Figure 2 Unfolding kinetic curves of RNases $\mathrm{H}$ at $25^{\circ} \mathrm{C}$. (A) Curves 1 and 2 represent the unfolding traces to a final concentration of 4.8 and 3.8 M GdnHCl of Tm-RNase HIl at pH 7.5. (B) Curves 1 and 2 represent the unfolding traces to a final concentration of 4.0 and $3.5 \mathrm{M} \mathrm{GdnHCl}$ of Aa-RNase HII at pH 5.0. (C) Curves 1 and 2 represent the unfolding traces to a final concentration of 7.5 and $7.0 \mathrm{M} \mathrm{GdnHCl}$ of Sto-RNase HI at $\mathrm{pH}$ 3.0. The lines represent the fit of Eq. (5).

The $\mathrm{k}_{\mathrm{u}}\left(\mathrm{H}_{2} \mathrm{O}\right)$ value for $\mathrm{GdnHCl}$-induced unfolding at $25^{\circ} \mathrm{C}$ is $6.5 \times 10^{-7} \mathrm{~s}^{-1}$ for Tm-RNase HII, $3.7 \times 10^{-5} \mathrm{~s}^{-1}$ for Aa-RNase HII, and $5.7 \times 10^{-11} \mathrm{~s}^{-1}$ for Sto-RNase HI (Table 3). The results indicate that Aa-RNase HII unfolds in water on a time scale similar to that of Ec-RNase $\mathrm{HI}$ and Tt-RNase HI. In contrast, Sto-RNase HI has remarkably slow unfolding characteristics, as in the case of Tk-RNase HII. The unfolding of Tm-RNase HII is slower than that 


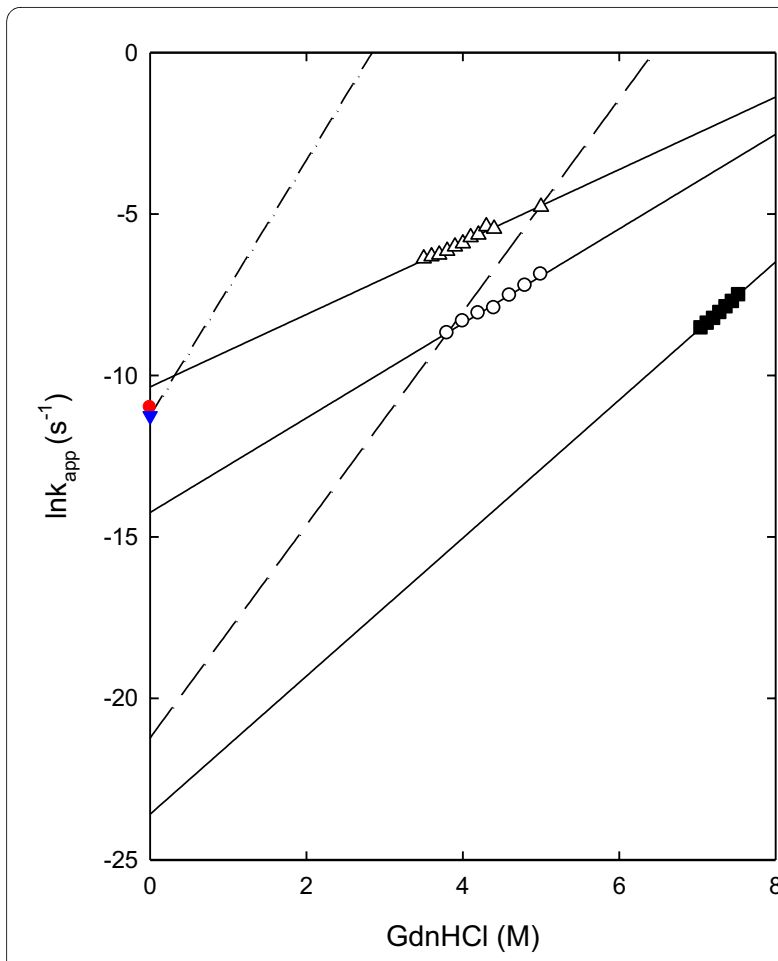

Figure $3 \mathrm{GdnHCl}$ concentration dependence of the apparent rate constant ( $I n \mathrm{k}_{\mathrm{app}}$ ) of the unfolding of RNases $\mathrm{H}$ at $25^{\circ} \mathrm{C}$. Open circles represent the data of $\mathrm{Tm}$ - $\mathrm{RNase} \mathrm{HII}$ at $\mathrm{pH}$ 7.5; open triangles, that of Aa-RNase HII at pH 5.0; and closed squares, that of Sto-RNase HI at $\mathrm{pH}$ 3.0. The lines represent the fit of Eq. (6). Long dashed line represent the data of Tk-RNase HII and one-point dashed line represent Ec-RNase $\mathrm{HI}[19,31]$. The red circle and blue triangles represents the $\mathrm{k}_{\mathrm{u}}\left(\mathrm{H}_{2} \mathrm{O}\right)$ value obtained from urea-induced unfolding experiments with Ec-RNase $\mathrm{HI}$ [33] and Tt-RNase HI [21], respectively.

of Ec-RNase HI, but the difference is much less than that between Ec-RNase HI and Sto-RNase HI. Thus, TmRNase HII does not show the extremely slow unfolding reactions.

For Tk-RNase HII and Sto-RNase HI, which exhibit slow unfolding, the experimental conditions were $\mathrm{pH} 9.0$ [19] and $\mathrm{pH} 3.0$, respectively, because the proteins unfold reversibly at each of these $\mathrm{pH}$ conditions. At neutral $\mathrm{pH}$ where these proteins do not show completely reversible unfolding, the $\mathrm{k}_{\mathrm{u}}\left(\mathrm{H}_{2} \mathrm{O}\right)$ value due to $\mathrm{GdnHCl}$-induced unfolding at $25^{\circ} \mathrm{C}$ was not very different from the value obtained under reversible conditions. For example, the $\mathrm{k}_{\mathrm{u}}\left(\mathrm{H}_{2} \mathrm{O}\right)$ value was $9.3 \times 10^{-10} \mathrm{~s}^{-1}$ for Tk-RNase HII at $\mathrm{pH}$ 7.5 and $3.3 \times 10^{-11} \mathrm{~s}^{-1}$ for Sto-RNase HI at pH 5.5. Therefore, Tk-RNase HII and Sto-RNase HI unfold extremely slowly at neutral $\mathrm{pH}$.

It should be noted here that the differences in the unfolding rates of hyperstable RNases $\mathrm{H}$ reflect the organism kingdom from which the host microorganisms of RNases $\mathrm{H}$ originate, i.e., archaea or bacteria. RNases $\mathrm{H}$ from thermophilic bacteria, such as Tt-RNase HI, AaRNase HII, and Tm-RNase HII unfold faster than similar proteins from thermophilic archaea, Sto-RNase HI, and Tk-RNase HII. This finding is supported by data from other monomeric proteins with reversible unfolding. TmCsp and Aa-S16 from hyperthermophilic bacteria do not exhibit extremely slow unfolding [24-27].

\section{Origin of super slow unfolding}

As described above, the nature of slow unfolding depends on the evolutionary history of the organisms. What is the difference between thermophilic archaeal and bacterial proteins? Berezovsky \& Shakhnovich [57] reported that proteins from archaea that originated in a hot environment are more compact and hydrophobic than their mesophilic homologs. In contrast, proteins from some bacteria, such as $\mathrm{Tm}$, that recolonized at a later stage under extreme conditions are stabilized by specific interactions such as salt bridges. Mizuguchi et al. [58] have shown differences in the amino acid composition of archaeal and bacterial proteins. They concluded that thermal adaptation is achieved in different ways in the archaeal and bacterial kingdoms.

The pie diagrams shown in Figures $4 \mathrm{~A}, 4 \mathrm{~B}$, and $4 \mathrm{C}$ depict the fraction of hydrophobic, polar, and charged residues in the interior of the tertiary structure of hyperstable RNases H. Because the structure of Aa-RNase HII has not been solved and some regions in the crystal structure of Tm-RNase HII have not been determined, we used the structures of Tt-RNase HI, Sto-RNase HI, and Tk-RNase HII. The results reveal that Sto-RNase HI and Tk-RNase HII from archaea are richer in hydrophobic residues than Tt-RNase $\mathrm{HI}$ from bacteria. This indicates that super slow unfolding in water is related to the amount of buried hydrophobic residues. The strong effect of hydrophobic interactions on the slow unfolding of Tk-RNase HII supports this hypothesis [18]. We also calculated the fractions of buried amino acid residues of other hyperstable RNase $\mathrm{H}$ homologs, the crystal structures of which have been determined. Similar to StoRNase HI and Tk-RNase HII, RNases HII from the hyperthermophilic archaea Pyrococcus furiosus (1UAX) and Archaeoglobus fulgidus (1I39) have more buried hydrophobic residues than Tt-RNase HII (see additional file 4). Furthermore, phylogenetic trees based on thermostable RNases HI and HII clearly show the difference in the characteristics of archaea and bacteria proteins (see additional file 5). These results suggest that archaeal RNases $\mathrm{H}$ are stabilized by super slow unfolding but bacterial RNases $\mathrm{H}$ are not.

We also calculated the buried area of the polar $(\mathrm{O}$ and $\mathrm{N})$ and nonpolar (C and S) atoms in the interior of the proteins because the buried area contributes to protein stability [59]. The buried areas of nonpolar atoms in TtRNase HI, Sto-RNase HI, and Tk-RNase HII were $62.6 \%$, $67.3 \%$, and $64.5 \%$, respectively (see additional file 6). Surprisingly, there was no significant difference between 
A

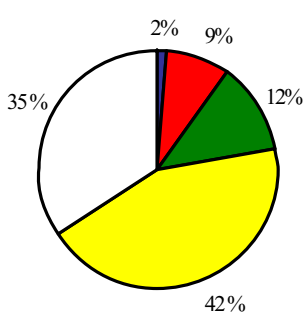

B

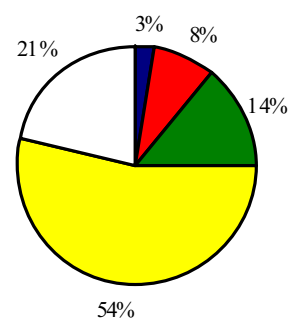

C

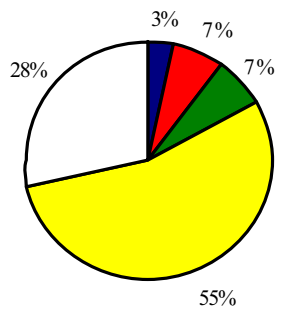

D

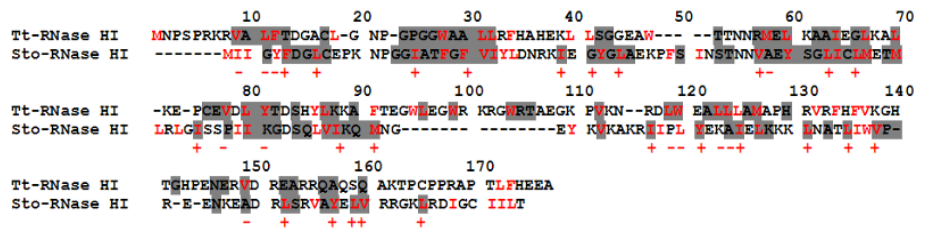

E

$\begin{array}{lllllll} & 10 & 20 & 30 & 40 & 50 & 60\end{array}$ TM-RNase HII MGIDELYKKE FG-IVAGVDE AGRGCLAGPV VAAAVLE-- --KEIEGIN- -DSKQISPAK RERLIDETME

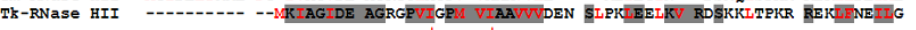

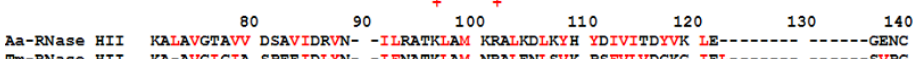

Tm-RNase HII KA-AVGIGIA SPEEIDIYN- -IFNATKLAM NRALENLSVK PSFVIVDGKG IEL---------SVPG

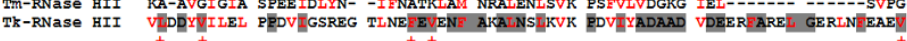

$\begin{array}{llllll}150 & 160 & ++ & & & + \\ 170 & 180 & 190 & 200 & 210\end{array}$

Aa-RNase HII MPLVKGDERS INCACASIIA KVIRDKIMEI YHKLYPDNE ASNKGYPSKT HLEKVE--KG EYTEIHRKS

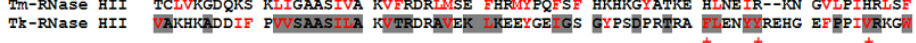

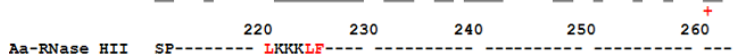

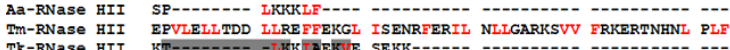

F

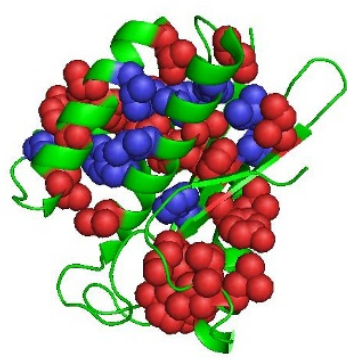

G

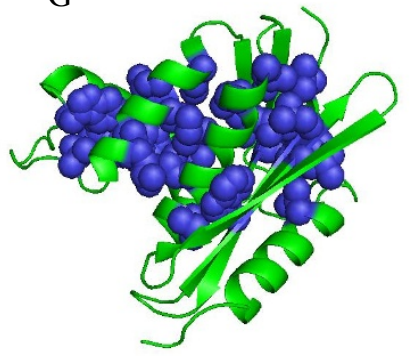

$\mathrm{H}$

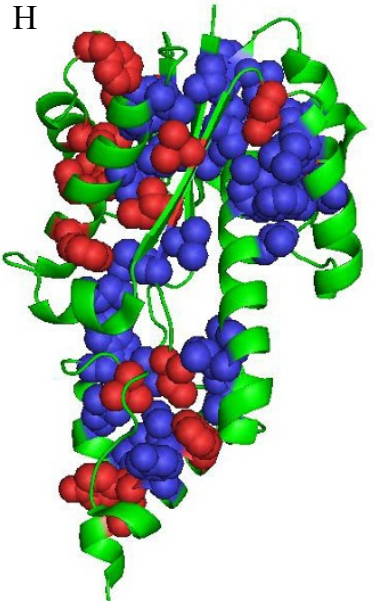

Figure $\mathbf{4}$ Characteristics of RNases $\mathbf{H}$. (A-C) Pie diagrams representing the fraction of hydrophobic, polar, and charged residues in the interior of the tertiary structure of hyperstable RNases H. (A) Tt-RNase HI. (B) Sto-RNase HI. (C) Tk-RNase HII. Blue denotes positively charged residues (Arg and Lys). Red denotes negatively charged residues (Asp and Glu). Green denotes polar residues (Asn, Gln, Ser, and Thr). Yellow denotes hydrophobic residues (Ile, Leu, Met, Phe, Trp, Tyr, and Val). White denotes other residues (Ala, Cys, Gly, His, and Pro). Amino-acid residues with relative solvent accessibility greater than 25\% were regarded as residues exposed to solvent [67]. (D and E) Amino acid sequence alignments of hyperstable RNases H. (D) RNases HI. (E) RNases HII. Buried residues (Tt, Sto and Tk) and hydrophobic residues are shown in gray and red, respectively. Crosses indicate buried hydrophobic residues in Sto-RNase HI and Tk-RNase HII with non-buried or non-hydrophobic counterpart in Tt-RNase HI and Aa/Tm-RNases HII, respectively. Minuses indicate buried hydrophobic residues in Tt-RNase HI with non-buried or non-hydrophobic counterpart in Sto-RNase HI. (F-H) Crystal structures of hyperstable RNases H. (F) Tt-RNase HI. (G) Sto-RNase HI. (H) Tk-RNase HII. Buried hydrophobic side-chains (relative solvent accessibility less than 25\%) are represented by sphere (blue and red). The buried hydrophobic residues in Sto-RNase HI and Tk-RNase HII with nonburied or nonhydrophobic counterpart in Tt-RNase $\mathrm{HI}$ and Aa/Tm-RNases HII are shown in red. The figures were created by PyMOL [68]. 
bacterial and archaeal proteins, although the hydrophobicity of archaeal RNases H (Sto-RNase HI and Tk-RNase HII) was higher than that of bacterial RNase H (Tt-RNase HI). Therefore, we suggest that the overall hydrophobicity, calculated from the buried area of atoms, does not differ greatly between bacterial and archaeal proteins and contributes to their equilibrium stability. The equlibrium stability of Sto-RNase HI, which is the most hydrophobic RNase $\mathrm{H}$, is considerably higher than that of Tt-RNase HI and Tk-RNase HII (Figure 1). It has been reported that $100 \AA^{2}$ of buried nonpolar atoms contributes to an equilibrium stability of about $15 \mathrm{~kJ} \mathrm{~mol}^{-1}$ [59]. In contrast, the estimate from the sequence/structure data (the fractions of amino acid residues in the interior of proteins) differs between bacterial and archaeal proteins [57,58], as described above. This suggests that the hydrophobic interaction arising from the partially exposed hydrophobic side chains may affect the unfolding rate (see below).

Figures 4D and 4E represent the amino acid sequence alignments, buried residues (Tt, Sto and Tk), and hydrophobic residues of thermophilic RNases H. In RNases HI, Sto-RNase HI has 24 buried hydrophobic residues with nonburied or nonhydrophobic counterparts in Tt-RNase $\mathrm{HI}$, whereas Tt-RNase HI has 11 such residues. Tk-RNase HII also possesses 10 buried hydrophobic residues with nonhydrophobic counterparts in Aa-RNase HII and TmRNase HII. These residues in Sto-RNase HI and TkRNase HII may be possible causes of the slow unfolding rate. These results will be confirmed in the near future by amino acid substitution experiments. Figures 4F, 4G, and $4 \mathrm{H}$ show the crystal structures of the buried hydrophobic residues of Tt-RNase HI, Sto-RNase HI, and Tk-RNase HII. Among RNases HI, Sto-RNase HI has more buried hydrophobic residues than Tt-RNase HI. Furthermore, it seems that the the 24 buried hydrophobic residues in StoRNase HI, which have nonburied or nonhydrophobic counterparts in Tt-RNase HI, are located near the surface of the protein. Tk-RNase HII also shows a similar tendency. The results suggest that buried hydrophobic sidechains near the protein surface may contribute to slow unfolding. Unfortunately, at present, the mechanism of slow unfolding by buried hydrophobic side-chains near the protein surface remains unclear.

\section{Energy diagram of the stability and folding of hyperstable proteins}

It has been reported that some hyperthermophilic proteins have a remarkably slow unfolding rate but a normal refolding rate in comparison with their homologous mesophilic proteins [6,8]. Tk-RNase HII unfolds extremely slowly but folds rapidly [19]. In contrast, TtRNase HI, which has thermostability equivalent to that of Tk-RNase HII, unfolds and folds quickly, similar to the behavior of Ec-RNase HI $[19,21]$. We can consider the energy diagrams of the folding process (see additional file 7). The first is for a mesophilic protein and is a two-state model. The second is for hyperstable proteins with super slow unfolding, whereas the third is for hyperstable proteins without super slow unfolding. In the second model, the increase in the equilibrium stability $(\Delta \mathrm{G})$ between the native and denatured states is accompanied by an increase in the unfolding barrier ( $\mathrm{N}$ to $\mathrm{T}$ ). In contrast, the third model includes an intermediate state in the folding process, which results in an increase in $\Delta \mathrm{G}$ without an increase in either the folding or unfolding barriers. It has been reported that although Tt-RNase HI has an intermediate folding state, Tk-RNase HII folds according to the two-state model $[19,36,60]$. Therefore, Tt-RNase HI and Tk-RNase HII are represented by the third and second models, respectively. For Aa-RNase HI and Tm-RNase $\mathrm{HI}$, the refolding experiments show that there is an intermediate state in the folding process (data not shown), suggesting that these proteins can be represented by the third model. When Sto-RNase HI folds according to the two-state model, $\mathrm{k}_{\mathrm{f}}\left(\mathrm{H}_{2} \mathrm{O}\right)=9.3 \times 10 \mathrm{~s}^{-1}, \mathrm{mf}=-2.98 \mathrm{M}^{-1} \mathrm{~s}^{-1}$, and $\Delta \mathrm{G}_{\text {kinetics }}\left(\mathrm{H}_{2} \mathrm{O}\right)=73.9 \mathrm{~kJ} \mathrm{~mol}^{-1}$ (unpublished data). This indicates that Sto-RNase HI is represented by the second model. On the other hand, the tetrameric protein Pf-PCP both folds and unfolds quite slowly [6]. Therefore, this protein is represented by the fourth model, in which the increase in equilibrium stability $(\Delta \mathrm{G})$ between the native and denatured states is accompanied by increases in both the unfolding ( $\mathrm{N}$ to $\mathrm{T}$ ) and folding ( $\mathrm{D}$ to $\mathrm{T}$ ) barriers. As a result, the unfolding barrier of the fourth model is higher than that of the second model. The unfolding rate of Pf-PCP $\left(1.6 \times 10^{-15} \mathrm{~s}^{-1}\right)$ is lower than those of Tk-RNase HII and Sto-RNase HI $\left(6.0 \times 10^{-10} \mathrm{~s}^{-1}\right.$ and $\left.5.7 \times 10^{-11} \mathrm{~s}^{-1}\right)[6]$.

\section{Conclusion}

In summary, we have presented the stability and unfolding kinetics of hyperstable RNases $\mathrm{H}$. This is a good protein family for investigating the stability and folding mechanisms from the viewpoints of thermal adaptation and evolution because the proteins are in the monomeric form and undergo reversible unfolding. Although different mechanisms are responsible for the equilibrium stabilization of hyperstable RNases $\mathrm{H}$, unfolding depends on the evolutional history of the host organisms from which the proteins originate. This has led to the use of different strategies for thermal adaptation by thermophilic archaea and bacteria.

\section{Methods \\ Construction of plasmids}

Plasmids pET800TM and pET600AA, used for overproduction of Tm-RNase HII and Aa-RNase HII, were con- 
structed by ligating 714bp and 588bp DNA fragments, respectively, into the NdeI-SalI sites of pET25b (Novagen). The DNA fragments were amplified by PCR using the genomic DNA of Tm and Aa as a template. The sequences of the PCR primers for Tm-RNase HII are 5'GAAAGGAGACGGCATATGGGAATAGATGA-3' for the 5' primer and 5'-GCGGTCGACCTTTGTGTTCGGAGATAAAG-3' for the 3' primer, and the PCR primers for Aa-RNase HII are 5'-AACCATATGCTTAATTACGAATTAGAACTTTG-3' for the 5' primer and 5'-GCGGTCGACCTAAAAAAGTTTTTTCTTAAGGGG-3' for the 3 ' primer, where the bold bases indicate the positions of the NdeI and SalI sites. The DNA sequence of the PCR products was confirmed with a Prism 310 DNA sequencer (Perkin-Elmer).

\section{Overproduction and purification}

E. coli BL21(DE3) was transformed with pET800TM and pET600AA then grown in NZCYM medium (Novagen) containing $50 \mathrm{mgL}^{-1}$ ampicillin $30 \mathrm{mgL}^{-1}$ chloramphenicol at $30^{\circ} \mathrm{C}$. When the optical density at $660 \mathrm{~nm}$ of the culture reached 0.5, $1 \mathrm{mM}$ IPTG was added to the culture medium and cultivation continued at $30^{\circ} \mathrm{C}$ for four hours. Cells were transformed with pET800TM, harvested by centrifugation at $8000 \mathrm{rpm}$ for $10 \mathrm{~min}$, suspended in 20 $\mathrm{mM}$ Tris- $\mathrm{HCl}(\mathrm{pH}$ 8) containing $10 \mathrm{mM}$ EDTA, disrupted by sonication lysis, and centrifuged at $30,000 \mathrm{~g}$ for $30 \mathrm{~min}$. The supernatant was subjected to heat treatment at $75^{\circ} \mathrm{C}$ for $20 \mathrm{~min}$ and centrifuged at 30,000 $\mathrm{g}$ for $30 \mathrm{~min}$. The supernatant was applied to an anion-exchange column (5 $\mathrm{mL}$ ) of a HiTrap Q HP column (Amersham Biosciences) equilibrated with $20 \mathrm{mM}$ Tris- $\mathrm{HCl}(\mathrm{pH} 8)$. The protein was eluted from the column with $20 \mathrm{mM}$ Tris- $\mathrm{HCl}(\mathrm{pH} 8)$ containing $10 \mathrm{mM}$ EDTA. The flow-through containing the protein was pooled and applied to a Hitrap Heparin and SP column (Amersham Biosciences) equilibrated with the same buffer. After the column was washed, the protein was eluted from the column with a linear gradient of $\mathrm{NaCl}$ from 0 to $1 \mathrm{M}$ in the same buffer. The fractions containing the protein were pooled and dialyzed against $20 \mathrm{mM}$ Tris- $\mathrm{HCl}$ (pH 8) containing $200 \mathrm{mM} \mathrm{NaCl}$. Cells were transformed with pET600AA, harvested by centrifugation at $8000 \mathrm{rpm}$ for $10 \mathrm{~min}$, suspended in $20 \mathrm{mM}$ Acetate- $\mathrm{NaOH}$ (pH 5.5) containing 10 mM EDTA, disrupted by French press lysis, and centrifuged at 30,000 $g$ for $30 \mathrm{~min}$. The supernatant was applied to an anionexchange column $(5 \mathrm{~mL})$ of a HiTrap Q HP column equilibrated with $20 \mathrm{mM}$ Acetate- $\mathrm{NaOH}$ (pH 5.5). The protein was eluted from the column with $20 \mathrm{mM}$ Acetate- $\mathrm{NaOH}$ (pH 5.5) containing $10 \mathrm{mM}$ EDTA. The flow-through containing the protein was pooled and applied to a Hitrap SP column equilibrated with the same buffer. After the column was washed, the protein was eluted from the column with a linear gradient of $\mathrm{NaCl}$ from 0 to $1 \mathrm{M}$ in the same buffer. The fractions containing the protein were pooled and dialyzed against $20 \mathrm{mM}$ Acetate- $\mathrm{NaOH}(\mathrm{pH}$ 5.0). The fractions containing the protein were pooled and applied to a Hitrap Heparin column equilibrated with the same buffer. After the column was washed, the protein was eluted from the column with a linear gradient of $\mathrm{NaCl}$ from 0 to $1 \mathrm{M}$ in the same buffer. The fractions containing the protein were pooled and dialyzed against 20 $\mathrm{mM}$ Acetate- $\mathrm{NaOH}$ ( $\mathrm{pH}$ 5.0).

Sto-RNase HI was overproduced and purified as previously described $[44,61]$. The purity of the protein was analyzed by SDS-PAGE using a $15 \%$ polyacrylamide gel, followed with Coomassie Brilliant Blue staining.

\section{Protein concentration}

The protein concentrations were estimated by assuming absorbances at $280 \mathrm{~nm}$ of 0.24 for $1 \mathrm{mgmL}^{-1} \mathrm{Tm}$-RNase HII and 0.89 for $1 \mathrm{mgmL}^{-1}$ Aa-RNase HII. These values were calculated using $1576 \mathrm{M}^{-1} \mathrm{~cm}^{-1}$ for Tyr and $5225 \mathrm{M}^{-}$ ${ }^{1} \mathrm{~cm}^{-1}$ for Trp at $280 \mathrm{~nm}$ [62].

\section{$\mathrm{CD}$ spectra measurements}

The CD spectra of Tm-RNase HII, Aa-RNase HII, and Sto-RNase HI in the absence and presence of GdnHCl were measured on a J-725 automatic spectropolarimeter (Japan Spectroscopic). The optical path length was $2 \mathrm{~mm}$ and the protein concentration was $0.16 \mathrm{mgml}^{-1}$. The buffers we used were $20 \mathrm{mM}$ Tris- $\mathrm{HCl}, 200 \mathrm{mM} \mathrm{NaCl}$ at $\mathrm{pH}$ 7.5 for $\mathrm{Tm}$-RNase HII, $20 \mathrm{mM}$ Acetate- $\mathrm{NaOH}$ at pH 5.0 for Aa-RNase HII, and $20 \mathrm{mM}$ Glycine- $\mathrm{NaOH}$ at $\mathrm{pH} 3.0$ for Sto-RNase HI. The measurements were done at $25^{\circ} \mathrm{C}$. For the spectra of a refolded protein, the protein that was completely unfolded at a 7.0 M GdnHCl concentration was diluted with buffer for refolding, and the diluted protein solution was incubated at the selected temperature until refolding reached equilibrium. The mean residue ellipticity, $\theta$, in units of degrees square centimeters per decimole, was calculated using an average amino acid molecular weight of 110 .

\section{Equilibrium experiments on GdnHCl-induced unfolding}

GdnHCl-induced unfolding was examined by monitoring the $\mathrm{CD}$ at $220 \mathrm{~nm}$ as described previously [19]. RNases $\mathrm{H}$ were incubated in $\mathrm{GdnHCl}$ at different concentrations and at different temperatures for unfolding. The Gdn$\mathrm{HCl}$-induced unfolding curves were determined, and a nonlinear least-squares analysis [63] was used to fit the data to

$$
\begin{aligned}
& \mathrm{y}=\left(\left(\mathrm{b}^{0}{ }_{\mathrm{n}}+\mathrm{a}_{\mathrm{n}}[\mathrm{D}]\right)\right. \\
& \left.+\left(\mathrm{b}^{0}{ }_{\mathrm{u}}+\mathrm{a}_{\mathrm{u}}[\mathrm{D}]\right) \exp \left(\left(\Delta \mathrm{G}\left(\mathrm{H}_{2} \mathrm{O}\right)-\mathrm{m}[\mathrm{D}]\right) / \mathrm{RT}\right)\right) / \\
& \left(1+\exp \left(\left(\Delta \mathrm{G}\left(\mathrm{H}_{2} \mathrm{O}\right)-\mathrm{m}[\mathrm{D}]\right) / \mathrm{RT}\right)\right)
\end{aligned}
$$




$$
\mathrm{C}_{\mathrm{m}}=\Delta \mathrm{G}\left(\mathrm{H}_{2} \mathrm{O}\right) / \mathrm{m}
$$

where $y$ is the observed $C D$ signal at a given concentration of $\mathrm{GdnHCl},[\mathrm{D}]$ is the concentration of $\mathrm{GdnHCl}, \mathrm{b}^{0}{ }_{\mathrm{n}}$ is the $\mathrm{CD}$ signal for the native state, $\mathrm{b}_{\mathrm{u}}{ }_{\mathrm{u}}$ is the $\mathrm{CD}$ signal for the unfolded states, $a_{n}$ is the slope of the pre-transition of the baseline, and $\mathrm{a}_{\mathrm{u}}$ is the slope of the posttransition of the baseline. $\Delta \mathrm{G}\left(\mathrm{H}_{2} \mathrm{O}\right)$ is the Gibbs energy change $(\Delta \mathrm{G})$ of the unfolding in the absence of $\mathrm{GdnHCl}, \mathrm{m}$ is the slope of the linear correlation between $\Delta \mathrm{G}$ and the Gdn$\mathrm{HCl}$ concentration $[\mathrm{D}]$, and $\mathrm{C}_{\mathrm{m}}$ is the $\mathrm{GdnHCl}$ concentration at the midpoint of the curve. The raw experiment data were directly fitted to Eq. (1) using SigmaPlot (Jandel Scientific). The equilibrium experiments were conducted in $20 \mathrm{mM}$ Tris- $\mathrm{HCl}, 200 \mathrm{mM} \mathrm{NaCl}$ at $\mathrm{pH} 7.5$ for TmRNase HII, $20 \mathrm{mM}$ Acetate- $\mathrm{NaOH}$ at $\mathrm{pH} 5.0$ for AaRNase HII, and $20 \mathrm{mM}$ Glycine- $\mathrm{NaOH}$ at pH 3.0 for StoRNase HI. To use Tris- $\mathrm{HCl}$ buffer at different temperatures, the $\mathrm{pH}$ was adjusted at $25^{\circ} \mathrm{C}$ so that the final $\mathrm{pH}$ would be 7.5 at the desired temperature [64]. The protein concentration when the $\mathrm{CD}$ measurements were taken was $0.16 \mathrm{mgmL}^{-1}$.

\section{Stability curves}

$\Delta \mathrm{G}\left(\mathrm{H}_{2} \mathrm{O}\right)$ was examined at various temperatures to determine the stability curves for Tm-RNase HII, Aa-RNase HII, and Sto-RNase HI. The stability curves obtained were fitted to the Gibbs-Helmholtz equation, Eq. (3):

$$
\begin{aligned}
& \Delta \mathrm{G}\left(\mathrm{H}_{2} \mathrm{O}\right)=\Delta \mathrm{H}\left(\mathrm{T}_{\mathrm{o}}\right)-\mathrm{T} \Delta \mathrm{S}\left(\mathrm{T}_{\mathrm{o}}\right) \\
& +\Delta \mathrm{C}_{\mathrm{p}}\left(\mathrm{T}-\mathrm{T}_{\mathrm{o}}-\mathrm{T} \ln \left(\mathrm{T} / \mathrm{T}_{\mathrm{o}}\right)\right)
\end{aligned}
$$

where $\Delta \mathrm{H}\left(\mathrm{T}_{\mathrm{o}}\right)$ and $\Delta \mathrm{S}\left(\mathrm{T}_{\mathrm{o}}\right)$ are the enthalpy and entropy of unfolding at the reference temperature $T_{o}$, and $\Delta C_{p}$ is the difference in heat capacity between the native and unfolded states.

\section{Heat-induced unfolding experiments}

Heat-induced unfolding was examined by monitoring the $\mathrm{CD}$ at $220 \mathrm{~nm}$. CD measurements were carried out on a J725 automatic spectropolarimeter as described previously [65]. The optical path length was $2 \mathrm{~mm}$. The thermal denaturation curves of these proteins were measured in the presence of various concentrations of $\mathrm{GdnHCl}$ to determine the $\mathrm{T}_{\mathrm{m}}$ values of Tm-RNase HII and Aa-RNase $\mathrm{HII}$ in the absence of $\mathrm{GdnHCl}$, where thermal denaturation of these proteins is not reversible. The buffer used was $20 \mathrm{mM}$ Tris- $\mathrm{HCl}, 200 \mathrm{mM} \mathrm{NaCl}$ at $\mathrm{pH} 7.5$ in the presence of 1.0 to $2.0 \mathrm{M} \mathrm{GdnHCl}$ for Tm-RNase HII and $20 \mathrm{mM}$ Acetate- $\mathrm{NaOH}$ at $\mathrm{pH} 5.0$ in the presence of 1.2 to 2.0 M GdnHCl for Aa-RNase HII. The thermal denaturation of these proteins was reversible under these condi- tions. The protein concentration was $0.16 \mathrm{mgml}^{-1}$. All experiments were carried out at a scan rate of $1{ }^{\circ} \mathrm{Cmin}^{-1}$. A nonlinear least-squares analysis [66] was used to fit the data to

$$
\begin{aligned}
& \mathrm{y}=\left(\left(\mathrm{b}_{\mathrm{n}}+\mathrm{a}_{\mathrm{n}}[\mathrm{T}]\right)\right. \\
& \left.+\left(\mathrm{b}_{\mathrm{n}}+\mathrm{a}_{\mathrm{u}}[\mathrm{T}]\right) \exp \left(\left(\Delta \mathrm{H}_{\mathrm{m}} / \mathrm{RT}\right)\left(\left(\mathrm{T}-\mathrm{T}_{\mathrm{m}}\right) / \mathrm{T}_{\mathrm{m}}\right)\right)\right) \\
& /\left(1+\exp \left(\left(\Delta \mathrm{H}_{\mathrm{m}} / \mathrm{RT}\right)\left(\left(\mathrm{T}-\mathrm{T}_{\mathrm{m}}\right) / \mathrm{T}_{\mathrm{m}}\right)\right)\right)
\end{aligned}
$$

where $y$ is the observed $C D$ signal at a given temperature $[T], b_{n}$ is the CD signal for the native state, $b_{u}$ is the $C D$ signal for the unfolded states, $a_{n}$ is the slope of the pretransition of the baseline, $a_{u}$ is the slope of the posttransition of the baseline, $\Delta \mathrm{H}_{\mathrm{m}}$ is the enthalpy of unfolding at the transition midpoint temperature $\left(\mathrm{T}_{\mathrm{m}}\right), \mathrm{T}$ is the temperature, and $\mathrm{R}$ is the gas constant. Curve fitting was performed using SigmaPlot. Because the $T_{m}$ values of these proteins increased in proportion to a decrease in $\mathrm{GdnHCl}$ concentration, the $\mathrm{T}_{\mathrm{m}}$ values in the absence of $\mathrm{GdnHCl}$ were estimated by linear extrapolation [46].

\section{Kinetic experiments on $\mathrm{GdnHCl}$-induced unfolding}

The unfolding reactions were followed by $\mathrm{CD}$ spectra measurement at $220 \mathrm{~nm}$, using $2 \mathrm{~mm}$ and $1 \mathrm{~cm}$ path length cuvettes as described previously [19]. CD measurements were conducted using a J-725 automatic spectropolarimeter. The unfolding reactions of proteins were induced by a concentration jump in $\mathrm{GdnHCl}$, with various differing concentrations. The protein solution was stirred using a spinning mixer with a magnetic stirrer in a cuvette with a $1 \mathrm{~cm}$ path length for the unfolding, and the $\mathrm{CD}$ was recorded at $220 \mathrm{~nm}$ as a function of time. The dead time of this method was $2 \mathrm{~s}$. The protein solution was stirred manually during use of a cuvette with a $2 \mathrm{~mm}$ path length. The dead time of this method was $10 \mathrm{~s}$. The kinetic experiments were performed in $20 \mathrm{mM}$ Tris- $\mathrm{HCl}$, $200 \mathrm{mM} \mathrm{NaCl}$ at $\mathrm{pH} 7.5$ for Tm-RNase HII, $20 \mathrm{mM}$ Acetate- $\mathrm{NaOH}$ at pH 5.0 for Aa-RNase HII, and $20 \mathrm{mM}$ Glycine- $\mathrm{NaOH}$ at pH 3.0 for Sto-RNase HI. The protein concentrations when $\mathrm{CD}$ measurements were taken were 0.0338 to $0.169 \mathrm{mgmL}^{-1}$. The kinetic data were analyzed using Eq. (5).

$$
\mathrm{A}(\mathrm{t})-\mathrm{A}(\infty)=A e^{-\mathrm{kt}}
$$

Here, $A(t)$ is the value of the CD signal at a given time $t$, $\mathrm{A}(\infty)$ is the value when no further change is observed, $\mathrm{k}$ is the apparent rate constant, and $\mathrm{A}$ is the amplitude. The $\mathrm{GdnHCl}$ concentration dependence of the logarithms of the apparent rate constant $\left(k_{\text {app }}\right)$ for unfolding was also examined. The rate constants for unfolding in the 
absence of $\mathrm{GdnHCl}\left(\mathrm{k}_{\mathrm{u}}\left(\mathrm{H}_{2} \mathrm{O}\right)\right)$ were calculated by fitting to Eq. (6):

$$
\ln \mathrm{k}_{\mathrm{app}}=\ln \mathrm{k}_{\mathrm{u}}\left(\mathrm{H}_{2} \mathrm{O}\right)+\mathrm{m}_{\mathrm{u}}[\mathrm{D}]
$$

where $[\mathrm{D}]$ is the concentration of $\mathrm{GdnHCl}$ and $\mathrm{m}_{\mathrm{u}}$ represents the slopes of the linear correlations of $\ln k_{u}$ with the $\mathrm{GdnHCl}$ concentration.

\section{Additional material}

\section{Additional file 1 Crystal structures of (A) Ec-RNase HI (PDB ID: 2RN2), (B) Tt-RNase HI (1RIL), (C) Sto-RNase HI (2EHG), (D) Tk-RNase HII (1IO2), and (E) Tm-RNase HII (2ETJ) \\ Additional file 2 Far-UV CD spectra of RNases $\mathrm{H}$ at $25^{\circ} \mathrm{C}$ Additional file $3 \mathrm{GdnHCl}$-induced denaturation curves of RNases $\mathrm{H}$ at $20^{\circ} \mathrm{C}$. \\ Additional file 4 Pie diagrams representing the fraction of hydropho- bic, polar, and charged residues in the interior of the tertiary structure of hyperstable RNases H. (A) RNase HII from Pyrococcus furiosus. (B) RNase HII from Achaeoglobus fulgidus. Accessible surface and buried area of RNases $\mathrm{H}$. \\ Additional file 5 Phylogenetic tree of thermostable RNases $\mathrm{H}$ on the basis of the amino acid sequences. \\ Additional file 6 Accessible surface and buried area of RNases $\mathrm{H}$ Additional file $7 \mathrm{Schematic}$ representations of the energy diagrams of the protein folding process}

\section{Abbreviations}

Aa: Aquifex aeolicus; CD: circular dichroism; Csp: cold shock protein; $\Delta \mathrm{G}\left(\mathrm{H}_{2} \mathrm{O}\right)$ : Gibbs energy change $(\Delta \mathrm{G})$ of the unfolding in water; Ec: Escherichia coli; Gdn$\mathrm{HCl}$ : guanidine hydrochloride; PCP: pyrrolidone carboxyl peptidase; Pf: Pyrococcus furiosus; RNase: ribonuclease; S16: ribosomal protein S16; Sto: Sulfolobus tokodaii; Tk: Thermococcus kodakaraensis; Tm: Thermotoga maritima; $\mathrm{T}_{\mathrm{m}}$ : thermal denaturation temperature; Tt: Thermus thermophilus

\section{Authors' contributions}

KT conceived and supervised the study. JO and TO conducted all experimental work. AM, TT, DJY and HC helped data analyses. YK and SK helped in interpretation of data and discussion of results. All authors read and approved the manuscript.

\section{Acknowledgements}

This work was supported in part by an Industrial Technology Research Grant Program from the New Energy and Industrial Technology Development Organization (NEDO) of Japan, and by a Grant from the Ministry of Education, Culture, Sports, Science, and Technology of Japan.

\section{Author Details}

1Department of Material and Life Science, Osaka University, 2-1 Yamadaoka, Suita, Osaka 565-0871, Japan and 2CREST, JST, 2-1 Yamadaoka, Suita, Osaka 565-0871, Japan

Received: 29 March 2010 Accepted: 9 July 2010

Published: 9 July 2010

\section{References}

1. Jaenicke R, Bohm G: The stability of proteins in extreme environments. Curr Opin Struct Biol 1998, 8:738-748.

2. Vieille C, Zeikus GJ: Hyperthermophilic enzymes: sources, uses, and molecular mechanisms for thermostability. Microbiol Mol Biol Rev 2001, 65:1-43

3. Perl D, Schmid FX: Some like it hot: The molecular determinants of protein thermostability. ChemBioChem 2002, 3:39-44.
4. Razvi A, Scholtz JM: Lessons in stability from thermophilic proteins. Protein Sci 2006, 15:1569-1578.

5. Cavagnero S, Debe DA, Zhou ZH, Adams MWW, Chan SI: Kinetic role of electrostatic interactions in the unfolding of hyperthermophilic and mesophilic rubredoxins. Biochemsitry 1998, 37:3369-3376.

6. Ogasahara K, Nakamura M, Nakura S, Tsunasawa S, Kato I, Yoshimoto T, Yutani K: The unusually slow unfolding rate causes the high stability of pyroolidone carboxyl peptidase from a hyperthermophilile Pyrococcus furiosus: Equilibrium and kinetic studies of guanidine hydrochlorideinduced unfolding and refolding. Biochemistry 1998, 37:17537-17544.

7. Dams T, Jaenicke R: Stability and folding of dihydrofolate reductase from the hyperthermophilic bacterium Thermotoga maritima. Biochemistry 1999, 38:9169-9178.

8. Kaushik JK, Ogasahara K, Yutani K: The unusually slow relaxation kinetics of the folding-unfolding of pyrrolidone carboxyl peptidase from a hyperthermophile. Pyrococcus furiosus. J Mol Biol 2002, 316:991-1003.

9. Jaswal SS, Sohl JL, Dans JH, Agard DA: Energetic landscape of alpha-lytic protease optimizes longevity through kinetic stability. Nature 2002, 415:343-346.

10. limura S, Yagi H, Ogasahara K, Akutsu H, Noda Y, Segawa S, Yutani K Unusually slow denaturation and refolding process of pyrrolidone carcoxyl peptidase from a hyper-thermophile are highly cooperative: Real-time NMR studies. Biochemistry 2004, 43:11906-11915.

11. Zeeb M, Lipps G, Lilie H, Balbach J: Folding and association of an extremely stable dimeric protein from Sulfolobus islandicus. J Mol Biol 2004, 336:227-240.

12. Forrer $P$, Chang $C$, Ott D, Wlodawer A, Plückthun A: Kinetic stability and crystal structure of the viral capside protein SHP. J Mol Biol 2004, 344:179-193.

13. Wittung-Stafshede P: Slow unfolding explains high stability of thermostable ferredoxins: common mechanism governing thermostability? Biochim Biophys Acta 2004, 1700:1-4.

14. Duy C, Fitter J: Thermostability of irreversible unfolding alpha-amylases analyzed by unfolding kinetics. J Biol Chem 2005, 280:37360-37365.

15. Kaushik JK, limura S, Ogasahara K, Yamagata Y, Segawa S, Yutani K. Completely buried, non-ion-paired glutamic acid contributes favorably to the conformational stability of pyrrolidone carboxyl peptidases from hyperthermophiles. Biochemistry 2006, 45:7100-7112.

16. Mishra R, Olofsson L, Karlsson M, Carlsson U, Nicholls IA, Hammarström P: A conformationally isoformic thermophilic protein with high kinetic unfolding barriers. Cell Mol Life Sci 2008, 65:827-839.

17. Costas M, Rodríguez-Larrea D, De Maria L, Borchert TV, Gómez-Puyou A, Sanchez-Ruiz JM: Between-species variation in the kinetic stability of TIM proteins linked to solvation-barrier free energies. J Mol Biol 2009, 385.924-937.

18. Dong H, Mukaiyama A, Tadokoro T, Koga Y, Takano K, Kanaya S: Hydrophobic effect on the stability and folding of a hyperthermophilic protein. J Mol Biol 2008, 378:264-272.

19. Mukaiyama A, Takano K, Haruki M, Morikawa M, Kanaya S: Kinetically robust monomeric protein from a hyperthermophile. Biochemistry 2004, 43:13859-13866.

20. Hollien J, Marqusee S: A thermodynamic comparison of mesophilic and thermophilic ribonucleases H. Biochemistry 1999, 38:3831-3836.

21. Hollien J, Marqusee S: Comparison of the folding processes of $T$. thermophilus and E. coli ribonucleases H. J Mol Biol 2002, 316:327-340.

22. Luke KA, Higgins CL, Wittung-Stafshede P: Thermodynamic stability and folding of proteins from hyperthermophilic organisms. FEBS $J 2007$ 274:4023-4033.

23. Mukaiyama A, Takano K: Slow unfolding of monomeric proteins from hyperthermophiles with reversible unfolding. Int J Mol Sci 2009, 10:1369-1385

24. Perl D, Welker C, Schindler T, Schröder K, Marahiel MA, Janicke R, Schmid FX: Conservation of rapid two-state folding in mesophilic, thermophilic and hyperthermophilic cold shock proteins. Nature Struct Biol 1998, 5:229-235.

25. Dominy BN, Perl D, Schmid FX, Brooks CLIII: The effect of ionic strength on protein stability: The cold shock protein family. J Mol Bio/ 2002, 319:541-554.

26. Schuler B, Kremer W, Kalbitzer HR, Jaenicke R: Role of entropy in protein thermostability: folding kinetics of a hyperthermophilic cold shock protein at high temperatures using 19F NMR. Biochemistry 2002, 41:11670-11680. 
27. Wallgren M, Adén J, Pylypenko O, Mikaelsson T, Johansson LB, Rak A, WolfWatz M: Extreme temperature tolerance of a hyperthermophilic protein coupled to residual structure in the unfolded state. $J \mathrm{Mol} B \mathrm{Bi} /$ 2008, 379:845-858.

28. Ohtani N, Haruki M, Morikawa M, Crouch RJ, Itaya M, Kanaya S: Identifiacation of the genes encoding $\mathrm{Mn}^{2+}$-dependent RNase $\mathrm{HII}$ and $\mathrm{Mg}^{2+}$-dependent RNase HIII from Bacillus subtilis: Classification of RNase $\mathrm{H}$ into these families. Biochemistry 1999, 38:605-618.

29. Ohtani N, Haruki M, Morikawa M, Kanaya S: Molecular diversities of RNase H. J Biosci Bioeng 1999, 88:12-19.

30. Yang W, Steitz TA: Recombining the structures of HIV integrase, RuvC and RNase H. Structure 1995, 3:131-134.

31. Yamasaki K, Ogasahara K, Yutani K, Oobatake M, Kanaya S: Folding pathway of Escherichia coli ribonucrease H: A circular dichroism, fluorescence and NMR study. Biochemistry 1995, 34:16552-16562.

32. Haruki M, Tanaka M, Motegi T, Tadokoro T, Koga Y, Takano K, Kanaya S: Structural and thermodynamic analyses of Escherichia coli RNase $\mathrm{HI}$ variant with quintuple thermostabilizing mutations. FEBS J 2007 274:5815-5825.

33. Raschke TM, Marqusee $\mathrm{S}$ : The kinetic folding intermediate of ribonuclease $\mathrm{H}$ resembles the acid molten globule and partially unfolded molecules detected under native conditions. Naure Struct Biol 1997, 4:298-304

34. Raschke TM, Kho J, Marqusee S: Confirmation of the hierarchical folding of RNase H: A protein engineering study. Naure Struct Biol 1999, 6:825-831.

35. Spudich GM, Miller EJ, Marquesee S: Destabilization of the Escherichia coli RNase $\mathrm{H}$ kinetic intermediate: Switching between a two-state and three-state folding mechanism. J Mol Biol 2004, 335:609-618.

36. Zhou Z, Feng H, Ghirlando R, Bai Y: The high-resolution NMR structure of the early folding intermediate of the Thermus thermophilus ribonuclease H. J Mol Biol 2008, 384:531-539.

37. Mukaiyama A, Haruki M, Ota M, Koga Y, Takano K, Kanaya S: A hyperthermophilic protein acquires function at the cost of stability. Biochemistry 2006, 45:12673-12679.

38. Mukaiyama A, Koga Y, Takano K, Kanaya S: Osmolyte effect on the stability and folding of a hyperthermophilic protein. Proteins: Struct Funct Bioinf 2008, 71:110-118.

39. Takano K, Higashi R, Okada J, Mukaiyama A, Tadokoro T, Koga Y, Kanaya S: Proline effect on the thermostability and slow unfolding of a hyperthermophilic protein. J Biochem 2008, 145:79-85.

40. Rohman MS, Koga Y, Takano K, Chon H, Crouch RJ, Kanaya S: Effect of the disease-causing mutations identified in human ribonuclease (RNase) $\mathrm{H} 2$ on the activities and stabilities of yeast RNase $\mathrm{H} 2$ and archaeal RNase HII. FEBS J 2008, 275:4836-4849.

41. Woese CR, Kandler O, Wheelis ML: Towards a natural system of organisms: Proposal for the domains Archaea, Bacteria, and Eucarya. Proc Natl Acad Sci USA 1990, 87:4576-4579.

42. Katayanagi K, Miyagawa M, Matsushima M, Ishikawa M, Kanaya S, Nakamura H, Ikehara M, Matsuzaki T, Morikawa K: Structural details of ribonuclease $\mathrm{H}$ from Escherichia coli as refined to an atomic resolution. J Mol Biol 1992, 223:1029-1052

43. Ishikawa K, Okumura M, Katayanagi K, Kimura S, Kanaya S, Nakamura H, Morikawa K: Crystal structure of ribonuclease $\mathrm{H}$ from Thermus thermophilus HB8 refined at 2.8 A resolution. J Mol Biol 1993, 230:529-542.

44. You DJ, Chon H, Koga Y, Takano K, Kanaya S: Crystal structure of type 1 ribonuclease $\mathrm{H}$ from hyperthermophilic archaeon Sulfolobus tokodaii: role of arginine 118 and C-terminal anchoring. Biochemistry 2007, 461:1494-1503.

45. Muroya A, Tsuchiya D, Ishikawa M, Haruki M, Morikawa M, Kanaya S, Morikawa K: Catalytic center of an archaeal type2 ribonuclease $\mathrm{H}$ as revealed by X-ray crystallographic and mutational analyses. Protein Sci 2001, 10:707-714

46. Tadokoro T, You DJ, Abe Y, Chon H, Matsumura H, Koga Y, Takano K, Kanaya S: Structural, thermodynamic, and mutational analyses of a psychrotrophic RNase HI. Biochemistry 2007, 46:7460-7468.

47. Tadokoro T, Matsushita K, Abe Y, Rohman MS, Koga Y, Takano K, Kanaya S: Remarkable stabilization of a psychrotrophic RNase $\mathrm{HI}$ by a combination of thermostabilizing mutations identified by the suppressor mutation method. Biochemistry 2008, 47:8040-8047.
48. Rohman MS, Tadokoro T, Angkawidjaja C, Abe Y, Matsumura H, Koga Y, Takano K, Kanaya S: Destabilization of psychrotrophic RNase HI in a localized fashion as revealed by mutational and X-ray crystallographic analyses. FEBS J 2009, 276:603-613.

49. Nojima H, Ikai A, Oshima T, Noda H: Reversible thermal unfolding of thermostable phosphoglycerate kinase. Thermostability associated with mean zero enthalpy change. J Mol Biol 1977, 116:429-442.

50. Razvi A, Scholtz JM: A thermodynamic comparison of HPr proteins from extremophilic organisms. Biochemistry 2006, 45:4084-4092.

51. McCrary BS, Edmondson SP, Shriver JW: Hyperthermophile protein folding thermodynamics: Differential scanning calorimetry and chemical denaturation of Sac7d. J Mol Biol 1996, 264:784-805.

52. Li WT, Grayling RA, Sandman K, Edmondson S, Shriver JW, Reeve JN: Thermodynamic stability of archaeal histones. Biochemistry 1998, 37:10563-10572

53. Grättinger M, Dankesreiter A, Schurig $H$, Jaenicke R: Recombinant phosphoglycerate kinase from the hyperthermophilic bacterium Thermotoga maritima: Catalytic, spectral and thermodynamic properties. J Mol Biol 1998, 280:525-533.

54. Deutschman WA, Dahlquist FW: Thermodynamic basis for the increased thermostability of CheY from the hyperthermophile Thermotoga maritima. Biochemistry 2001, 40:13107-13113.

55. Lee CF, Allen MD, Bycroft M, Wong KD: Electrostatic interactions contribute reduced heat capacity change of unfolding in a thermophilic ribosomal protein L30e. J Mol Biol 2005, 348:419-431.

56. Chon H, Tadokoro T, Ohtani N, Koga Y, Takano K, Kanaya S: Identification of RNase HII from psychrotrophic bacterium. Shewanella sp, SIB1 as a high-activity type RNase H. FEBS J 2006, 273:2264-2275.

57. Berezovsky IN, Shakhnovich El: Physics and evolution of thermophilic adaptation. Proc Nat/ Acad Sci USA 2005, 102:12742-12747.

58. Mizuguchi K, Sele M, Cubellis MV: Environment specific substitution tables for thermophilic proteins. BMC Bioinformatics 2007, 8(Suppl 1):S15.

59. Funahashi J, Takano K, Yutani K: Are the parameters of various stabilization factors estimated from mutant human lysozymes compatible with other proteins? Protein Eng 2001, 14:127-134.

60. Ratcliff K, Corn J, Marqusee S: Structure, stability, and folding of ribonuclease $\mathrm{H} 1$ from the moderately thermophilic Chlorobium tepidum: comparison with thermophilic and mesophilic homologues. Biochemistry 2009, 48:5890-5898.

61. You DJ, Chon H, Koga Y, Takano K, Kanaya S: Crystallization and preliminary crystallographic analysis of type $1 \mathrm{RNase} \mathrm{H}$ from the hyperthermophilic archaeon Sulfolobus tokodaii 7. Acta Crystallogr Sect F Struct Biol Cryst Commun 2006, 62:781-784.

62. Goodwin TW, Morton RA: The spectrophotometric determination of tyrosine and tryptophan in proteins. Biochem J 1946, 40:628-632.

63. Pace CN: Measuring and increasing protein stability. Trends Biotechnol 1990, 8:93-98.

64. Good NE, Winget GD, Winter W, Connolly TN, Izawa S, Singh RMM: Hydrogen ion buffers for biological research. Biochemistry 1966 5:467-477.

65. Takano K, Saito M, Morikawa M, Kanaya S: Mutational and structuralbased analyses of the osmolyte effect on protein stability. J Biochem 2004, 135:701-708.

66. Santoro MM, Bolen BW: Unfolding free energy changes determined by the linear extrapolation method. 1. Unfolding of phenylmethanesufonyl alpha-chymotrypsin using different denaturants. Biochemistry 1988, 27:8063-8068.

67. You DJ, Fukuchi S, Nishikawa K, Koga Y, Takano K, Kanaya S: Protein thermostabilization requires a fine-tuned placement of surfacecharged residues. J Biochem 2007, 142:507-516.

68. DeLano WL: PyMOL User's Guide. DeLano Scientific San Carlos, California; 2004

doi: 10.1186/1471-2148-10-207

Cite this article as: Okada et al., Evolution and thermodynamics of the slow unfolding of hyperstable monomeric proteins BMC Evolutionary Biology 2010, $10: 207$ 